\title{
DENTAL AND ORAL LESIONS IN HIV-POSITIVE INDIVIDUALS IN EAST BOHEMIA - CZECH REPUBLIC, SINGLE CENTRE EXPERIENCE
}

\author{
Martin Šembera, Vladimíra Radochová, Radovan Slezák
}

Department of Dentistry, Charles University in Prague, Faculty of Medicine and University Hospital in Hradec Králové, Czech Republic

Summary: Background: Human immunodeficiency virus (HIV) continues to be a serious health issue and one of the world most devastating epidemics. An estimated 1.5 million people died from AIDS-related illnesses in 2013, and an estimated 37 million people with AIDS have died worldwide since the epidemic has begun. HIV infection is known for its oral manifestations which causes discomfort and pain for infected individuals. The objective of this study was to document oral conditions of HIV positive patients and the pattern and frequency of oral and dental lesions. Methods: All patients with confirmed HIV infection who were treated at the Department of Dentistry, University Hospital in Hradec Králové, were examined. Results: During the study period, 29 HIV positive patients were examined and treated - 19 men, 10 women, with mean age of 32.9 years (range 22-58 years). $72.41 \%$ patients received ART. In total, all patients underwent 186 visits. The most frequent treatments were associated with teeth and periodontal lesions $(71.80 \%)$, oral mucosal lesions were diagnosed and treated only in 3.96\% cases. Conclusion: Since the introduction of ART, the frequency of oral mucosal lesions is minimal in patients with HIV infection.

Keywords: HIV; Dental lesions; Oral mucosal lesions

\section{Introduction}

Human immunodeficiency virus (HIV) which causes acquired immunodeficiency syndrome (AIDS) continues to be a very serious health issue and one of the world's most devastating epidemics. According to the WHO documents $(1,2)$ there were about 2.1 million new cases of HIV in 2013 worldwide. About 35 million people are living with HIV all around the world. An estimated 1.5 million people died from AIDS-related illnesses in 2013 and an estimated 37 million people suffering from AIDS have died since the epidemic has begun. Sub-Saharan Africa bears the biggest burden of HIV/AIDS, with nearly one in 20 adults living with HIV. Other regions significantly affected by HIV/AIDS include Latin America, the Caribbean, Eastern Europe, Central Asia, South and Southeast Asia.

The history of AIDS in medicine started in 1981 in USA where the disease was firstly described including oral signs. Discovery of HIV as the cause of AIDS was done later from blood samples originated from Central Africa. The virus was initially identified by Luc Montanier in 1983 (3) and then was fully characterized in 1984 by Robert Gallo (4-7). Later, two different types of the virus, HIV-1 and HIV-2, were recognized (8).

The objective of this study was to document oral conditions in a cohort of HIV-positive individuals and the pattern and frequency of oral mucosal and dental lesions including the treatment need found during their appointments at the Department of Dentistry, Faculty of Medicine and University Hospital in Hradec Králové, Czech Republic. This information was expected to give us a fair estimation of an impact of the HIV infection on their oral health.

\section{Material and methods}

A cohort of 29 adult HIV-positive individuals was examined at the Department of Dentistry, Faculty of Medicine and University Hospital in Hradec Králové from January 2000 to September 2013 (according to cumulative data from 1 October 1985 to 31 January 2014 of National Laboratory of references for AIDS, there were 39 HIV positive individuals diagnosed in East Bohemia (9)). All these patients were simultaneously treated at the Department of Infectious Diseases, University Hospital in Hradec Králové. Both departments serve as parts of the AIDS Centre in Hradec Králové, one of seven AIDS Centres in Czech Republic.

Each patient received a comprehensive oral and perioral examination focused on current dental, periodontal and mucosal status including radiographic examination, as well. Smears and biopsies were taken to verify the diagnosis, if necessary. All examinations were conducted by certified clinical specialists. 
Following dental and oral lesions were noted: Dental caries and its complications, mostly pulpitis, pulp necrosis and apical periodontitis; plaque-related periodontal disease, e. g., gingivitis and periodontitis; salivary glands disease; mucosal disorders, e. g., herpes simplex infection, oral lichen planus, candidiasis, Kaposi sarcoma, non-specified oral ulcerations. Appropriate treatment and advice were administered. Following characteristics were also noted: Gender, age, stage of the HIV-related disease according to the WHO (10), treatment mode of the HIV infection, other systemic infectious diseases. The study has been performed according to the Declaration of Helsinki, and the procedures have been approved by the local ethics committee (reference number 201504 S16P, date of submission 26 March 2015). No statistical analysis was performed due to the small count of patients.

\section{Results}

Within the study time period, 29 HIV-positive individuals were referred to the Department of Dentistry. 19 patients $(65.3 \%)$ were males, and 10 patients $(34.8 \%)$ were females. The age of patients was from 22 to 58 years, with the mean age of 32.9 ( $+/-8.9$ years). Gender, age, clinical staging of the HIV infection, treatment mode and comorbidities are summarized in Table 1.

Tab. 1: Distribution of demographic and clinical data of HIV positive patients.

\begin{tabular}{|l|c|}
\hline \multicolumn{1}{|c|}{ Gender } & n \\
\hline Male Age (in years) & 19 \\
\hline Female & 10 \\
\hline $20-24 \quad$ Clinical staging (WHO) & 4 \\
\hline $25-29$ & 8 \\
\hline $30-34$ & 9 \\
\hline $35-39$ & 6 \\
\hline $40-49 \quad 1$ & 1 \\
\hline $50-59$ & 14 \\
\hline & 5 \\
\hline Category A (stage II) & 10 \\
\hline Caregory B (stage III) & \\
\hline Category C (stage IV) & 7 \\
\hline HIV treatment & 1 \\
\hline Non & 10 \\
\hline Prophylaxis & 11 \\
\hline ART & \\
\hline ART + prophylaxis & \\
\hline Comorbidities (systemic disease) & \\
\hline
\end{tabular}

\begin{tabular}{|l|l|}
\hline Tuberculosis & 3 \\
\hline HIV encephalophaty & 2 \\
\hline Lues & 2 \\
\hline Herpes zoster & 3 \\
\hline CMV & 2 \\
\hline Hepatitis & 3 \\
\hline Bacterial pneumonia & 1 \\
\hline Wasting syndrome & 1 \\
\hline Toxoplasmosis & 1 \\
\hline Klebsiela & 1 \\
\hline Arbovirosis & 1 \\
\hline
\end{tabular}

* Some patients had more than one systemic disease.

According to the WHO clinical staging of the HIV/ AIDS, 14 patients $(48.3 \%)$ were of stage II, 5 patients $(17.2 \%)$ of stage III and 10 patients $(34.5 \%)$ of stage IV. 21 patients $(72.4 \%)$ received active antiretroviral treatment (ART) or active antiretroviral treatment combined with antibiotic prophylaxis. 8 patients $(37.6 \%)$ recieved no therapy.

Infectious systemic diseases included tubercolosis and viral hepatitis, both in 3 cases $(10.3 \%)$, herpes zoster, lues, CMV disease and HIV encephalopathy, all in 2 cases (6.9\%). We have also observed one case of a bacterial pneumonia, toxoplasmosis, Klebsiella infection and arbovirosis (each $3.5 \%$ ). Oral pain and discomfort was the most frequent complaints of evaluated individuals occuring 131 times during 186 visits $(70.4 \%)$. Oral and dental lesions are summarized in Table 2.

Tab. 2: Patients dental and oral diagnose.*

\begin{tabular}{|l|c|}
\hline \multicolumn{1}{|c|}{ Dental leasion } & n \\
\hline Dental caries & 16 \\
\hline Pulpitis & 16 \\
\hline Tooth pulp necrosis & \\
\hline Periodontal disease & 23 \\
\hline \multicolumn{1}{|c|}{ Oral mucosal leasion } & 2 \\
\hline Periodontitis & \\
\hline & 3 \\
\hline Candidosis & 1 \\
\hline Herpes simplex virus & 1 \\
\hline Non-recurrent oral ulceration & 1 \\
\hline Haemangiom & 1 \\
\hline Kaposi sarcoma & 1 \\
\hline Erosive oral lichen planus & 1 \\
\hline Sialoadenitis & \\
\hline
\end{tabular}

*Some patients had more than one disease/lession. 


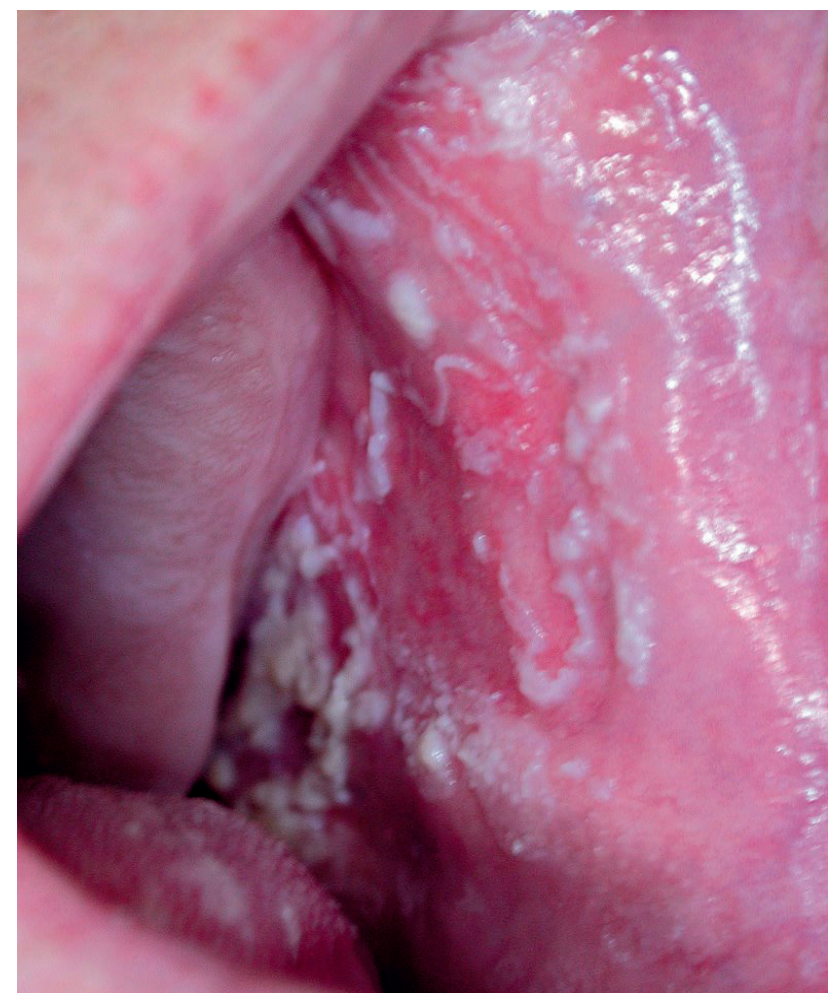

Fig. 1: Acute pseudomembranous form of the oral candidasis of the bucal mucosa. Typical white lesions combined with redness in surroundings.

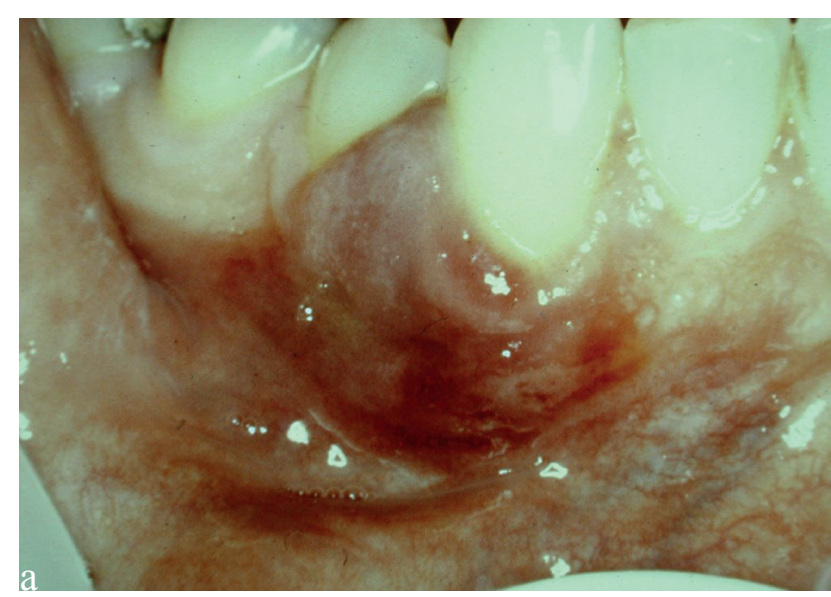

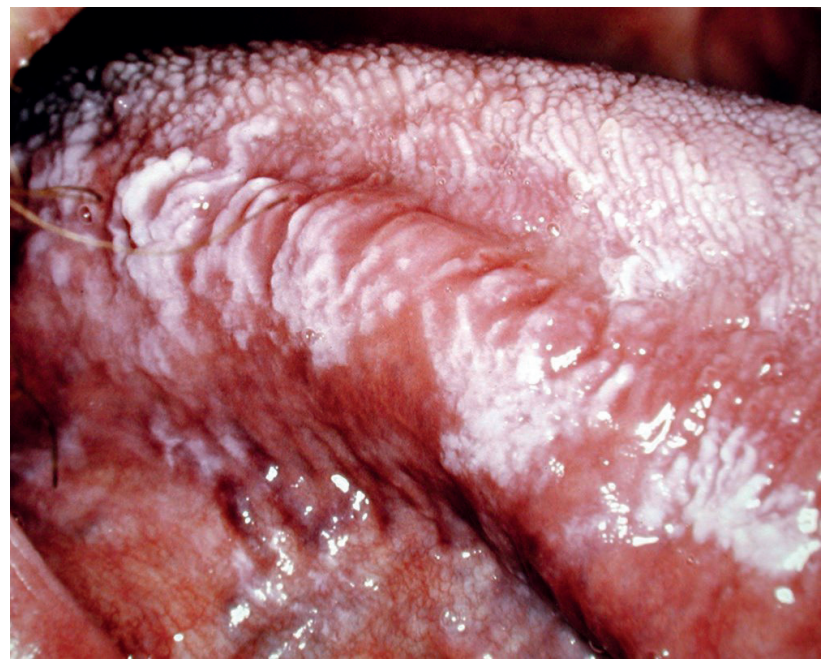

Fig. 3: Hairy leukoplakia, a chronic viral infection caused by Epstein-Barr virus, known for 40 years in the association with HIV.

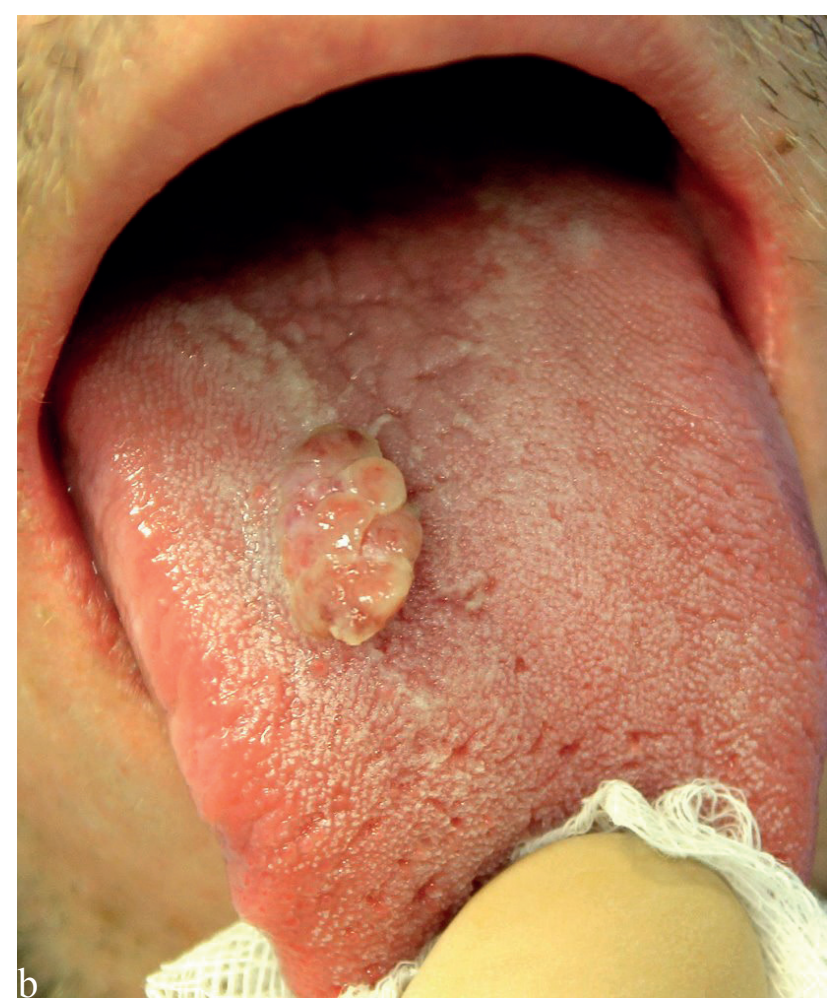

Fig. 2: Typical form of the Kaposi sarcoma of the gingiva (a) and an atypical exophytic form of the tongue tumor (b).

The most common diagnoses were chronic form of the plaque-induced gingivitis in 23 patients $(79.3 \%)$, pulp necrosis in 16 patients $(55.2 \%)$, tooth decay in 16 patients $(55.2 \%)$, pulpitis in four patients $(13.8 \%)$, and apical periodontitis in two patients $(6.9 \%)$. Only 7 patients $(24.1 \%)$ revealed one type of oral mucosal lesions, one of them $(3.45 \%)$ with two types of various mucosal le- sions simultaneously. The most frequent oral lesion was oral candidosis detected in three patients (10.3\%) (Fig. 1). Other oral mucosal diagnoses such as intraoral herpes simplex, non-specified oral ulcerations, erosive form of the oral lichen planus, haemangioma, Kaposi sarcoma, and sialoadenitis of the parotid gland, were seen in each one individual (Fig. 2, 3). 


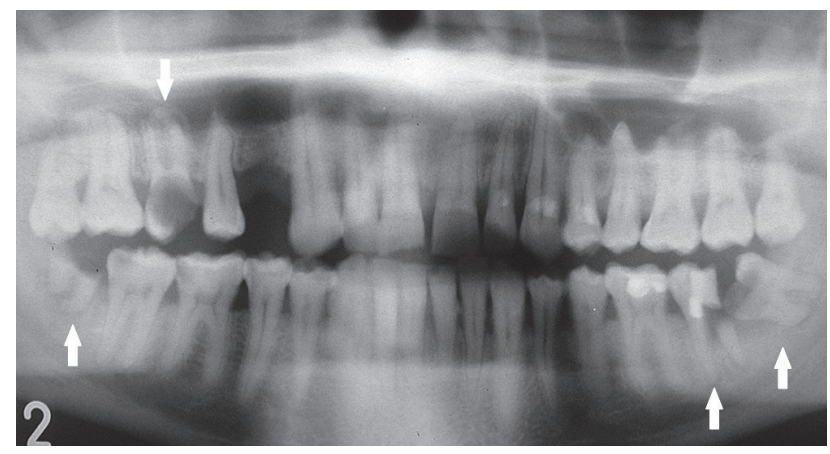

Fig. 4: Panoramic radiograph of the dentition of an HIV-positive younger individual. Note posterior teeth 16, 37, 38, 48 (arrows) fully destroyed by dental decay and indicated for extractions.

In total, the cohort of patients underwent 186 dental visits. The most frequent treatment procedures were associated with teeth and periodontal lesions $(71.8 \%)$, and oral mucosal lesions were treated in 9 visits (4\%). 79 restorative treatment of dental caries $(34.8 \%)$ were done. Due to the extensive destruction of the crown, 38 teeth $(16.7 \%)$ needed extractions (Fig. 4). Periodontal diseases were treated in $25(11 \%)$ cases. The patients also underwent 13 endodontic treatment procedures $(5.7 \%)$, and 7 prostethics restorative procedures $(3.08 \%)$. A surgical procedure was needed in one patient to treat persistant oroantral comunication after the extraction of an upper molar $(0.4 \%)$. All therapeutic procedures are summarized in Table 3.

Tab. 3: Distribution of dental and oral lesion treatment.

\begin{tabular}{|l|c|}
\hline & n \\
\hline Preventive treatment & 55 \\
\hline Restorative treatment (filling) & 79 \\
\hline Endodontic treatment & 13 \\
\hline Extraction & 38 \\
\hline Wassmund plastic & 1 \\
\hline Crown & 7 \\
\hline Periodontal disease treatment & 25 \\
\hline Oral lesion treatment & 9 \\
\hline
\end{tabular}

\section{Discussion}

The majority of patients in our study were male (65.3\%). A similar findings were reported by Ranganathanet (77.4\%)
(11), Nittayananta (72.5\%) (12), Sharma (72.2\%) (13), and Bendick (60.3\%) (14). Different gender distribution in a similar study was described by Adedigba with $36.4 \%$ of female patients (15). The median age for both genders was 32.9 years.

That means practically no differences in comparizon with other clinical studies (Bendick 32 years (14), Nittayananta 28 years (12)).

The most frequent patient's oral complaint was acute pain. If untreated, in HIV positive individuals can result in odynophagia and/or dysphagia which may lead to serious problems with chewing and swallowing. This fact could be followed by a dehydratation, rapid weight loss and malnutrition resulting to the HIV-wasting syndrome. It interferes with already damaged immune system response $(16,17)$. In general, $70.4 \%$ of dental examinations were conditioned by the presence of an acute oral pain, comparable to the study of Agbelusi (18), who recorded pain in $80 \%$. There is only one study by Pinheiro (19) concerning prevalence of dental caries treatment need (see Table 4 for comparison). Our results of the dental treatment need and preventive treatment need were similar. Restorative treatment need was twice higher as in the study mentioned above $(78.9 \%)$, compared to our results $(34.8 \%)$. In $6.2 \%$ cases in Pinheiro's study, a tooth had to be extracted (19), on the other hand, in our study tooth extraction was indicated in $16.7 \%$ only.

The most common mucosal lesion associated with HIV infection in our cohort was oral candidiasis as a very frequent fungal infection found in immunocompromised individuals. Necrotizing periodontal disease, inraoral herpes, herpes zoster, non-specified oral ulcers and Kaposi sarcoma in the oral cavity also caused pain $(20,21,22)$. Interestingly, our findings showed that mucosal manifestations of the HIV infection were present in $27.6 \%$ of our HIV-positive patients only, which coresponds with results of Pinheiro $(33.5 \%)$ in 2004 (19). On the other hand, different studies showed much higher prevalence of mucosal lesions, e. g., 60.4\% in a study published by Arendorf (23), 79.2\% by Sharma (13), $86 \%$ by Ranganathan (11), and $90 \%$ by Bendick (14). Oral candidiasis was the most frequent mucosal lesion among HIV-positive patients in this study in 3 of 29 patients $(10.3 \%)$. This was far less frequent than reported by Sharma (13) 44.5\%, Agbelusi (18) 43\%, and Arendorf (23) where oral candidiasis was evident in $37.8 \%$. Lower prevalence rate $(13.7 \%)$ was also reported by Schuman (24). Since the patients with oral candidosis had already been given antimycotics prophylacticaly, therapeutical dosage of antimycotics was prescribed.

Tab. 4: Percentage prevalence of dental lesion treatment needs comparison (in percentages).

\begin{tabular}{|l|c|c|c|c|c|}
\hline \multicolumn{1}{|c|}{ Study } & $\begin{array}{c}\text { Dental treatment } \\
\text { need }\end{array}$ & $\begin{array}{c}\text { Preventive } \\
\text { treatment }\end{array}$ & $\begin{array}{c}\text { Restoreative } \\
\text { treatment }\end{array}$ & $\begin{array}{c}\text { Endodontic } \\
\text { treatment }\end{array}$ & Extraction \\
\hline A. Pinheiro et. al & 78.9 & 26.1 & 77.6 & 0 & 6.2 \\
\hline Our study & 85 & 24.2 & 34.8 & 5.7 & 16.7 \\
\hline
\end{tabular}


Since there are seven AIDS Centres in the Czech Republic, it would be very informative to compare our findings with others. This would give us a fair idea of the problem across our country. Unfortunately, there are no similar retrospective analyses done in the Czech Republic.

\section{Conclusion}

Since the introduction of ART in clinical practice and early testing for the infection, in 2013, about 12.9 million people living with HIV had access to antiretroviral therapy (9), and the frequency of oral mucosal lesion had become significantly less frequent (25). If this trend continues, HIV/ AIDS will become more manageable and such patients will be able to live without major problems and limitations related to their relatively good oral health. Nonetheless even with good care and available medication for HIV infection, people shouldn't stop taking precautions again this infection.

\section{Acknowledgements}

Supported by the research project PRVOUK P37/13.

\section{References}

1. WHO. Epidemiological fact sheet on HIV/AIDS. UNAIDS 2014. (Internet). UNAIDS; available from: http://www.unaids.org/sites/default/files/en/media/unaids /contentassets/documents/factsheet/2014/20140716_FactSheet_en.pdf

2. WHO gap report epidemiology slides UNAIDS 2014 (Internet). UNAIDS; available from: http://www.unaids.org/en/media/unaids/contentassets/documents /document/2014/2014gapreportslides/01_Epi_slides_2014July.pdf

3. Barré-Sinoussi F, Chermann JC, Rey F, et al. Isolation of a T-lymphotropic retrovirus from a patient at risk for acquired immune deficiency syndrome (AIDS) Science 1983; 220: 868-71.

4. Popovic M, Sarngadharan MG, Read E, Gallo RC. Detection, isolation, and continuous production of cytopathic retroviruses (HTLV-III) from patients with AIDS and pre-AIDS. Science 1984; 224: 497-500

5. Gallo RC, Salahuddin SZ, Popovic M, et al. Frequent detection and isolation of cytopathic retroviruses (HTLV-III) from patients with AIDS and at risk for AIDS Science $1984 ; 224:$ 500-3.
6. Schüpbach J, Popovic M, Gilden RV, Gonda MA, Sarngadharan MG, Gallo RC. Serological analysis of a subgroup of human T-lymphotropic retroviruses (HTLVIII) associated with AIDS. Science 1984; 224: 503-5.

7. Sarngadharan MG, Popovic M, Bruch L, Schüpbach J, Gallo RC. Antibodies reactive with human T-lymphotropic retroviruses (HTLV-III) in the serum of patients with AIDS. Science 1984; 224: 506-8.

8. Hoy J. HIV Management in Australasia a guide for clinical care. Australasian Society for HIV Medicine (ASHM); 2009; 9-17.

9. SZU. Leden 2014: výskyt a šiřrení HIV/AIDS v České republice. (Internet); Available from: http://www.szu.cz/uploads/documents/CeM/HIV AIDS/rocni _zpravy/2014/HIV_AIDS_01_2014.pdf

10. Interim who clinical staging of HIV/AIDS and HIV/AIDS case definitions for surveillance (Internet). WHO; 2005; available from: http://www.who.int/hiv/pub /guidelines/clinicalstaging.pdf

11. Ranganathan K, Umadevi M, Saraswathi TR, Kumarasamy N, Solomon S, Johnson N. Oral lesions and conditions associated with human immunodeficiency virus infection in 1000 South Indian patients. Ann Acad Med Singapore 2004; 33(4 Suppl): $37-42$.

12. Nittayananta W, Chungpanich S. Oral lesions in a group of Thai people with AIDS. Oral Dis 1997; 3(Suppl 1): 41-5.

13. Sharma G, Pai KM, Suhas S, Ramapuram JT, Doshi D, Anup N. Oral manifestations in HIV/AIDS infected patients from India. Oral Dis 2006; 12(6): 537-42.

14. Bendick C, Scheifele C, Reichart PA. Oral manifestations in 101 Cambodians with HIV and AIDS. J Oral Pathol Med Off Publ Int Assoc Oral Pathol Am Acad Oral Pathol 2002; 31(1): 1-4.

15. Adedigba MA, Ogunbodede EO, Jeboda SO, Naidoo S. Patterns of oral manifestation of HIV/AIDS among 225 Nigerian patients. Oral Dis 2008; 14(4): 341-6.

16. Weinert M, Grimes RM, Lynch DP. Oral manifestations of HIV infection. Ann Intern Med 1996; 125(6): 485-96.

17. Sirois DA. Oral manifestations of HIV disease. Mt Sinai J Med N Y 1998; 65(5-6) 322-32

18. Agbelusi GA, Wright AA. Oral lesions as indicators of HIV infection among routine dental patients in Lagos, Nigeria. Oral Dis 2005; 11(6): 370-3.

19. Pinheiro A, Marcenes W, Zakrzewska JM, Robinson PG. Dental and oral lesions in HIV infected patients: a study in Brazil. Int Dent J 2004; 54(3): 131-7.

20. Neville B, Damm DD, Allen, CM, Bouquot JE. Oral and Maxillofacial Pathology. 3rd edition. St. Louis: Saunders; 2009.

21. Ryder MI, Nittayananta W, Coogan M, Greenspan D, Greenspan JS. Periodontal disease in HIV/AIDS. Periodontol 2000 2012; 60(1): 78-97.

22. Pantanowitz L, Khammissa RA, Lemmer J, Feller LJ. Oral HIV-associated Kapos sarcoma. Oral Pathol Med. 2013; 42(3): 201-7.

23. Arendorf TM, Bredekamp B, Cloete CA, Sauer G. Oral manifestations of HIV infection in 600 South African patients. J Oral Pathol Med Off Publ Int Assoc Oral Pathol Am Acad Oral Pathol 1998; 27(4): 176-9.

24. Schuman P, Ohmit SE, Sobel JD, Mayer KH, Greene V, Rompalo A, et al. Oral lesions among women living with or at risk for HIV infection. HIV Epidemiology Research Study (HERS) Group. Am J Med 1998; 104(6): 559-64.

25. Mthethwa SR, Wanjau J, Chabikuli N. The prevalence of HIV associated oral lesions among adults in the era of HAART. SADJ. 2013; 68(8): 364-71.

Received: $22 / 06 / 2015$

Accepted in revised form: 29/10/2015

\section{Corresponding author:}

MDDr. Martin Šembera, Department of Dentistry, University Hospital Hradec Králové, Sokolská 581, 50005 Hradec Králové, Czech Republic; e-mail: martin.sembera@fnhk.cz 